\title{
Impact of oral health conditions on the quality of life of workers
}

\author{
Maria Júlia Campos Guerra ${ }^{1}$ \\ Rosangela Maria Greco ${ }^{2}$ \\ Isabel Cristina Gonçalves Leite ${ }^{1}$ \\ Efigênia Ferreira e Ferreira ${ }^{3}$ \\ Marcos Vinícius Queiroz de Paula ${ }^{4}$
}

${ }^{1}$ Departamento de Saúde Coletiva, Faculdade de Medicina, Universidade Federal de Juíz de Fora (UFJF). Campus Universitário, Martelos. 36036-330 Juiz de Fora MG Brasil.

majuguerra@hotmail.com

${ }^{2}$ Departamento de

Enfermagem Básica,

Faculdade de Enfermagem, UFJF.

${ }^{3}$ Departamento de Odontologia Social e Preventiva, Faculdade de Odontologia, UFMG.

${ }^{4}$ Departamento de Clínica Odontológica, Faculdade de Odontologia, UFJF.

\begin{abstract}
Occupational health has been the scope of numerous studies, primarily due to the concern that the worker should enjoy good working conditions and a satisfactory quality of life. This study seeks to analyze the impact of oral health on the quality of life of workers at a public university using the simplified version of the Oral Health Impact Profile (OHIP-14) and associated factors. A cross-sectional study was conducted with 326 workers who responded the questions of OHIP-14 about self-rated health, oral morbidity, and socioeconomic and demographic questions. Multiple linear regression analysis was performed to verify the association between the independent variables and OHIP-14. About $40 \%$ of the impact of oral health on quality of life can be explained by the variables: education level $(p=0,03)$, age ( $p=$ $0,03)$, reason for visiting a dentist $(p=0,01)$, oral health perception $(p<0,01)$ and satisfaction with teeth and mouth $(p<0,01)$. The use of OHIP14 can be useful for planning programs and actions focused on health education for occupational health, prioritizing workers with greater psychosocial impacts caused by oral problems.

Key words Occupational health, Oral health, Sickness impact profile, Quality of life
\end{abstract}




\section{Introduction}

It is a known fact that oral modifications compromise the individual's general health, interfering negatively in his/her quality of life (QL) and affecting the productive activity of the worker. ${ }^{1}$

The field of oral health of the worker has as objective the relation between oral health and work in order to promote, preserve, and recover oral health of populations inserted in the various work processes, thus contributing to a better quality of life. ${ }^{2}$

Alterations related to the stomatognathic system may trigger painful stimuli or psychological and emotional problems that interfere directly in the performance of daily activities of the population, whether due to morbidity provoked by the pain, distracting the person's attention with the intention of alleviating discomfort, or due to a difficulty in interpersonal relationships resulting from the absence of dental elements. ${ }^{3}$

However, despite recognizing the importance of social and psychological aspects in determining disease, dentistry continues to use biological indexes in evaluating and determining the need for treatment and appreciation of oral health programs, such as the decayed, missing, filled teeth - DMFT index and the community periodontal index of treatment needs - CPITN. Nevertheless, such indexes do not take into consideration the individual's subjective perception and do not evaluate the way in which oral health affects daily life. ${ }^{4}$

For Petersen ${ }^{5}$ (2003), oral health extrapolates the concept of maintaining healthy teeth, and is an essential point for guaranteeing the individual's well-being, since it is inserted into the context of general health and interferes with quality of life. Clinical indexes are not capable of capturing damage, such as pain and interference in chewing and self-esteem; the inference of these aspects is assessed by means of questionnaires that measure the impact of oral health on quality of life. Thus, in order to recognize the impact of mouth diseases on a person's daily life, the term 'quality of life' related to oral health has been used by researchers.

Quality of life can be defined as a basically human notion that has been compared to the degree of satisfaction found in family, affectionate, social, and environmental life and in existential esthetics itself. It is assumed that the capacity to effect a cultural synthesis of all the elements that a specific society considers its standard of comfort and well-being. The term covers many meanings, which reflect knowledge, experiences, and values of individuals and communities. ${ }^{6}$

Quality of life related to oral health is determined by a variety of conditions that affect the individual's perception, his/her senses, and behavior in day-to-day life. Thus, a growing interest has been noted on the part of researchers to quantify the consequences of a disease that affects the routine of the person affected. ${ }^{7}$

Thus recognizing the importance of quality of life related to oral health, researchers have developed standardized questionnaires in order to assess it. Instruments capable of approaching psychological and social aspects by means of self-perception and evaluation of the impacts caused in quality of life have been developed and validated by various authors. Among them, we mention OIDP (Oral Impacts on Daily Performances), GOHAI (Geriatric Oral Health Assessment Index), and the OHIP-49 (Oral Health Impact Profile), and its shorter version, OHIP-14.

Observing that there are few studies addressing the subjective oral health indicators in populations of workers ${ }^{8-13}$, and considering that subjective indexes of oral health have been increasingly used in dentistry, the present study had as its objective to analyze the impact of oral health conditions on the quality of life of workers at a public university by means of the OHIP-14, and the factors associated with this impact.

\section{Methods}

The present study - Impact of oral health on quality of life of workers - is part of a cross-sectional exploratory research project - Technical Administrative Workers in Education: Working and Life Conditions. The survey was initiated with the First Inquiry on Working Conditions and Life of Workers at the Universidade Federal de Juiz de Fora (UFJF), applied to a sample of Technical Administrative Workers in Education (TAEs, acronym in Portuguese) from the UFJF, Minas Gerais, from February 2012 to January 2013.

The study entitled Technical Administrative Workers in Education: Working and Life Conditions is the starting point, the basis for development of a cohort prospective study at the university. In constructing this data collection instrument, previously tested and validated scales were used with the purpose of investigating issues related to working and life conditions of these workers. 
The survey was divided into 12 blocks, covering topics about the general health status, oral health, eating habits, physical activity, alcohol ingestion and smoking, relationships with family, with friends and at work, socioeconomic conditions, and demographic profiles, among others.

Considering that the primary interest of this study was to analyze the impact of oral health conditions on the quality of life of the TAEs at UFJF, it is important to emphasize a few points as to the questions analyzed and the block of the questionnaire in reference to oral health of the workers.

The first topic analyzed was on self-perception of general health. The second was about the 'single item of perceived oral health,' a measurement that incorporates the perception of the individual as to his/her own oral health. The richness of this measurement is illustrated by the strong association with relevant questionnaires on oral health, including topics relative to esthetics, chewing, comfort, psychological well-being, social relations, general and oral quality of life, and general health. ${ }^{14}$

In the first part of the block on oral health, 10 questions were used from the National Oral Health Research [Pesquisa Nacional de Saúde Bucal] ${ }^{15}$ - Projeto SBBrasil 2010, which ask about reported oral morbidity, use of dental services, and self-perception. In the second part, the OHIP-14 questionnaire was used to analyze the impacts of oral health conditions on the quality of life of workers. The OHIP-14 is the most often used instrument to evaluate the adverse impact caused by oral conditions on well-being and on quality of life of the individuals ${ }^{16}$.

In order to delineate the socioeconomic and demographic profile of the study's population, topics in reference to age, gender, level of schooling, marital status, and questions from the socioeconomic block were used for the economic classification as per the Brazilian Association of Research Companies (ABEP). The Brazil Economic Classification Criterion ${ }^{17}$ (CCEB) is an instrument of economic segmentation that uses the assessment of residential characteristics (presence and quantity of a few items of home comfort and level of schooling of the head of the family) to differentiate the population. The criterion attributes points according to the function of each home characteristic and sums up these points. Then a correspondence is made between the ranges of the mean gross monthly family income, in reals: A ( $\mathrm{R} \$ 9,263.00)$; B1 ( $\mathrm{R} \$ 5,241.00)$;
B2 (R\$ 2,654.00); C1 (R\$ 1,685.00); C2 (R\$ 1,147.00); DE (R\$776.00).

Before drawing up the final version of the questionnaire in order to perform possible adjustments in the data collection instrument and train the researchers, a pilot study was conducted in a population of subjects similar to those of this survey composed of 184 outsourced workers at UFJF who did not participate in this study. The reliability of the questionnaire was estimated by the internal consistency by means of McDonald's Alpha Ordinal and Omega coefficients, with results between 0.94 and 0.96 respectively. In the pilot study, the limitations of the study became evident, such as the incapacity to answer certain questions and the lack of clarity in some topics. Therefore, the necessary changes were made to overcome the perceived difficulties and better adjust the data collection instrument.

To calculate the sample, considering a total of 1,266 TAEs, a mean expected prevalence of $30 \%$ was used as parameter for perceived oral health, based on prior studies ${ }^{7,9,18}$. A 5\% error was estimated, along with a 95\% confidence interval, which resulted in 258 participants. To this value, $25 \%$ was added to compensate possible losses, resulting in a minimal sample of 325 individuals, with the expectation of reaching 258 valid questionnaires.

Included in the sample were the TAEs of UFJF, regardless of age and gender, who signed the Informed Consent. Excluded were the workers who at the time of collection were on loan to other institutions, or on vacation, or on leave for any reason. Therefore, we obtained a simple random sample of 326 individuals.

The data obtained was tabulated and analyzed using the Statistical Package for the Social Sciences (SPSS) version 15.0 and Microsoft Office Excel 2007.

Likert scale was used to score the answers to each question of the OHIP-14 with the following values: $0=$ never, $1=$ rarely, $2=$ sometimes, $3=$ frequently, 4 = always, with a maximal possible score of 56 points. Based on prior studies ${ }^{8,11,18}$, the answers to each question of OHIP-14 were dichotomized, and the presence of impact was defined as the answers 'frequently' and 'always', and for those without impact, the answers 'sometimes', 'rarely', and 'never'.

Data were analyzed by means of descriptive statistics, with distribution of absolute and percentage frequencies of all the study variables, as per the form (symmetry, asymmetry), central 
tendency (mean, median), and variability (standard deviation, total amplitude).

The means of each domain and of total OHIP-14 were verified for posterior comparison of means ${ }^{7,9,11,13,19,20}$.

For the bivariate analysis, statistical tests were used with the objective of determining the association between the OHIP-14 index and the independent variables. The normality of the dependent variables was tested using the Kolmogorov-Smirnov test, and the hypothesis of normality of distribution of data was refuted. Thus, we opted for the use of Mann-Whitney nonparametric test, with a $5 \%$ significance level.

As dependent variables, OHIP-14 and its seven domains were adopted (1: Functional limitation; 2: Physical pain; 3: Psychological discomfort; 4: Physical disability; 5: Psychological disability; 6: Social disability; 7: Deficiency). The independent variables adopted sought to translate the association between OHIP-14 and its dimensions and socioeconomic and demographic conditions, self-reported oral morbidity, self-perception, and the use of dental services of the study population.

The independent variables studied were dichotomized according to the mean or were grouped according to homogeneity or according to the distribution of frequencies, into categories, and reclassified for verification of association with the outcome.

Multiple linear regression analysis was made from the variables that showed a statistically significant association $(\mathrm{p}<0.05)$ with the total OHIP-14 in the bivariate analysis. The multivariate analysis was conducted in order to identify the predictors of OHIP-14, and was presented in three blocks, in the following order: 1: socioeconomic and demographic variables; 2 : socioeconomic and demographic variables and the variable of use of dental services; 3 : socioeconomic and demographic variables, variable of use of dental services, and variable of self-perception of oral morbidity.

This study was submitted to the Ethics in Research in Human Beings Committee of the UFJF and approved.

\section{Results}

This study population $(\mathrm{n}=326)$ was composed for the most part of men (52.0\%). The mean age was 44.01 years, with minimum age of 20 years and maximum of 67 years, and most had grad- uate level schooling (59.1\%). As to economic class, as per the Brazilian Association of Research Companies (ABEP), 56.4\% of workers belonged to class $\mathrm{B} 2$, with a gross monthly family income of $\mathrm{R} \$ 2,654.00$, i.e., approximately four minimum (monthly) wages, considering the current value of R\$ 678.00.

As to perception of health, $53.4 \%$ considered themselves as having good general health and $50.3 \%$, with good oral health. Most admitted the need for dental treatment $(54.2 \%)$ and $82.9 \%$ had had no dental pain in the previous six months. As to satisfaction with teeth and mouth, $50.0 \%$ were satisfied.

Regarding the use of dental services, $65.2 \%$ had gone to the dentist in less than a one-year period and most $(76.6 \%)$ had used a private service. Forty-nine point two (49.2\%) sought the dentist for a revision, prevention, or check-up, and $31.3 \%$ for treatment.

As to frequency of impact for each domain (Table 1), it is important to point out that Physical pain and Psychological discomfort showed the highest frequency $(6.5 \%)$, as well as the highest means (1.21 and 1.14, respectively). The mean total found for OHIP-14 was 4.55 (Figure 1).

The variables age $(p=0.01)$ and level of schooling $(\mathrm{p}=0.01)$ showed a significant association with the total OHIP-14. Older individuals, aged between 45 and 67 years, and workers without a college degree, showed the greatest impact of oral health condition on quality of life (Table 2).

All the variables of oral morbidity and self-perception analyzed showed a statistically significant association with the total OHIP-14 in the bivariate analysis. Those who acknowledged the need for dental treatment had the greatest impact on quality of life caused by oral conditions $(\mathrm{p}<0.01)$, as well as those who perceived

Table 1. Distribution of TAEs from UFJF, 2012, according to the frequency of impact, by domains ( $\mathrm{n}$ =326).

\begin{tabular}{lcr}
\hline Dimension of oral health & $\begin{array}{c}\text { No } \\
\text { impact } \\
\text { n(\%) }\end{array}$ & $\begin{array}{c}\text { With } \\
\text { impact } \\
\mathbf{n}(\%)\end{array}$ \\
\hline Physical limitation & $314(97,2)$ & $9(2,8)$ \\
Physical pain & $302(93,5)$ & $21(6,5)$ \\
Psychological discomfort & $302(93,5)$ & $21(6,5)$ \\
Physical incapacity & $313(97,2)$ & $9(2,8)$ \\
Psychological incapacity & $309(96,0)$ & $13(4,0)$ \\
Social incapacity & $321(99,7)$ & $1(0,3)$ \\
Disability & $322(100,0)$ & $0(0,0)$ \\
\hline
\end{tabular}




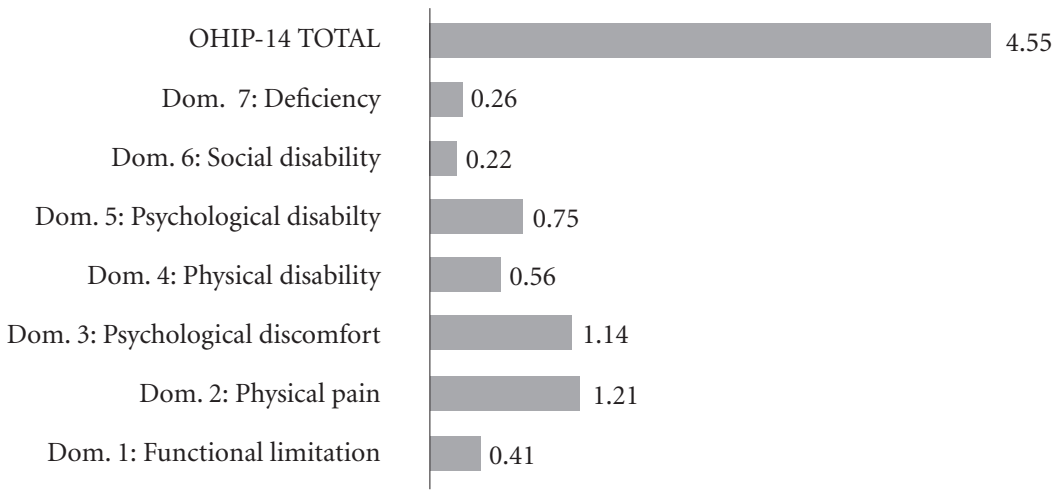

Figure 1. Mean total of OHIP-14 and by domains of the TAEs from UFJF, 2012 ( $\mathrm{n}=326$ ).

Table 2. Mean, standard deviation and p-value (Mann-Whitney) of the socioeconomic and demographic variables, of use of dental services, of self-perception, and self-reported oral morbidity, for total OHIP-14 of the TAEs from UFJF, $2012(\mathrm{n}=326)$.

\begin{tabular}{|c|c|}
\hline Variable & $\begin{array}{l}\text { OHIP-14 total } \\
\text { Mean (standard } \\
\text { deviation) }\end{array}$ \\
\hline \multicolumn{2}{|l|}{ Age } \\
\hline 20-44 years & $2.97(4.22)$ \\
\hline $45-67$ years & $7.27(4.41)$ \\
\hline p-value & 0.01 \\
\hline \multicolumn{2}{|l|}{ Level of schooling } \\
\hline Non-university & $6.49(7.760)$ \\
\hline University & $6.00(6.343)$ \\
\hline p-value & 0.01 \\
\hline \multicolumn{2}{|l|}{ Reason for dental appointment } \\
\hline Revision, prevention, check-up & $2.28(4.12)$ \\
\hline Pain, extraction, treatment, others & $6.64(7.32)$ \\
\hline p-value & $<0.01$ \\
\hline \multicolumn{2}{|l|}{ Self-referred need for treatment } \\
\hline Yes & $6.43(7.05)$ \\
\hline No & $2.13(4.56)$ \\
\hline p-value & $<0.01$ \\
\hline \multicolumn{2}{|l|}{ Perceived oral health } \\
\hline Poor & $10.12(8.54)$ \\
\hline Good & $2.49(3.83)$ \\
\hline p-value & $<0.01$ \\
\hline \multicolumn{2}{|l|}{ Perceived general health } \\
\hline Poor & $8.25(9.48)$ \\
\hline Good & $4.01(5.76)$ \\
\hline p-value & 0.02 \\
\hline \multicolumn{2}{|l|}{ Satisfaction with teeth and mouth } \\
\hline Not satisfied & $9.38(7.98)$ \\
\hline Satisfied & $2.24(3.69)$ \\
\hline p-value & $<0.01$ \\
\hline
\end{tabular}

their oral health as being poor $(p<0.01)$, those who perceived their general health as being poor $(p=0.02)$, and those who affirmed not being satisfied with their teeth and mouth $(\mathrm{p}<0.01)$ (Table 2).

For the variable of use of dental services, the reason for the last appointment made kept a statistically significant association with the total OHIP-14 ( $p<0.01)$. Those who sought the dentist for reasons of pain, extractions, treatment, or others different from prevention, showed a more negative impact of the conditions of oral health on quality of life (Table 2).

The multiple regression analysis revealed a 0.40 coefficient of determination, which means that about $40.0 \%$ of the impact of oral health conditions on quality of life measured by OHIP14 , in this group of workers, might be explained by the variables level of schooling, age, reason for dental appointment, perceived oral health, and satisfaction with teeth and mouth (Table 3 ).

\section{Discussion and conclusions}

This study had most of its population composed of men, but we note that the quantity of women TAEs was very expressive, which reveals the growing insertion of women in the work field, a fact explained by the combination of economic, cultural, and social factors. However, some authors affirm that even with the recent greater participation of women in the work force, the number of male workers is still greater ${ }^{11}$.

As to level of schooling, most of the population studied had done graduate school, which 


\begin{tabular}{|c|c|c|c|c|c|c|c|c|c|c|}
\hline \multirow[t]{17}{*}{ 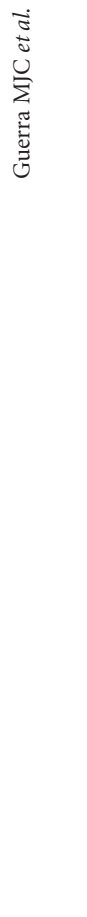 } & $\begin{array}{l}\text { Table 3. Multiple linear regression for } \\
\text { 326). }\end{array}$ & cotal OH & IIP-14, as per & rder of up & load of & he var & ables from & TAEs of U & JFJF, 20 & $12(n=$ \\
\hline & Block & B & $(95 \%) \mathrm{CI}$ & p-value & $\mathbf{R}$ & $\mathbf{R}^{2}$ & $\begin{array}{c}\text { Adjusted } \\
\qquad \mathbf{R}^{2}\end{array}$ & $\begin{array}{c}\text { Standard } \\
\text { error }\end{array}$ & $\mathbf{F}$ & p-value \\
\hline & 1 & & & & $0.22^{\mathrm{a}}$ & 0.05 & 0.04 & 6.08 & 7.73 & 0.01 \\
\hline & Level of schooling & -0.95 & $-2.93 \quad 1.03$ & 0.35 & & & & & & \\
\hline & Age & 2.44 & $1.02 \quad 3.86$ & 0.01 & & & & & & \\
\hline & 2 & & & & $0.39^{\mathrm{b}}$ & 0.15 & 0.15 & 5.74 & 17.80 & $<0.01$ \\
\hline & Level of schooling & 0.61 & $-1.46 \quad 2.68$ & 0.56 & & & & & & \\
\hline & Age & 2.14 & $0.76 \quad 3.52$ & 0.02 & & & & & & \\
\hline & Reason for dental appointment & 4.28 & $2.90 \quad 5.66$ & $<0.01$ & & & & & & \\
\hline & 3 & & & & $0.63^{c}$ & 0.40 & 0.39 & 4.85 & 27.37 & $<0.01$ \\
\hline & Level of schooling & 1.97 & $0.15 \quad 3.80$ & 0.03 & & & & & & \\
\hline & Age & 1.28 & $0.09 \quad 2.46$ & 0.03 & & & & & & \\
\hline & Reason for dental appointment & 2.10 & $0.84 \quad 3.36$ & 0.01 & & & & & & \\
\hline & Need for treatment & -0.80 & $-2.13 \quad 0.53$ & 0.24 & & & & & & \\
\hline & Perceived oral health & -3.59 & $-5.30-1.87$ & $<0.01$ & & & & & & \\
\hline & Perceived general health & -1.28 & $-3.14 \quad 0.58$ & 0.18 & & & & & & \\
\hline & Satisfaction with teeth and mouth & -4.11 & $-5.69-2.54$ & $<0.01$ & & & & & & \\
\hline
\end{tabular}

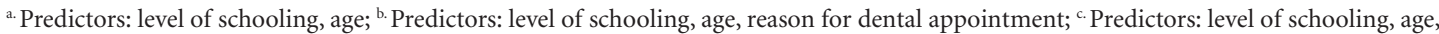
reason for dental appointment, need for treatment, perceived oral health, perceived general health, satisfaction with teeth and mouth.

can be explained by the fact that the TAEs are effective workers, and therefore, have a certain level of financial stability and career plans. Additionally, they are encouraged to continue their studies, which stimulates the worker to seek supplementation of his/her training.

We noted that the impact of oral health on quality of life was greater when the level of schooling was lower, similar to what was found in other studies ${ }^{8,12}$. This might be explained by the fact that the higher level of schooling is associated with a higher level of income and more information, which determines a greater search for dental services by this working population, which in turn implies a smaller impact on $\mathrm{QL}^{12}$.

The individual's level of schooling has a significant impact on his/her $\mathrm{QL}^{21}$. The higher the schooling level, the greater the information acquired and greater the search for dental services ${ }^{12}$.

As to economic classification, since most belong to class B2, we can affirm that this is a population of workers with good resources, not only financial, but also educational, which probably reflects in quality of life. As Silva and Fernandes ${ }^{22}$ confirm, the social environment is important, since life and working conditions afford a special qualification due to the manner in which the individuals think, feel, and act regarding their health.

However, in this study no associations were found between the economic class and the OHIP-
14 , a result similar to that of the study conducted by Bombarda-Nunes et al. ${ }^{8}$.

We can assert that the severity of the impact was reduced in our study, since the total mean of OHIP-14 was low, which also was noted by other authors. ${ }^{7,9}$

Montero et al. ${ }^{13}$ found higher means (9.60) with Spanish workers. Cohen-Carneiro et al. ${ }^{19}$, in a study with coastal riverside populations in the state of Amazonas, found higher mean levels for two communities (10.92 and 14.03). According to the authors, these results may be explained by the fact that access to dental services in this region is limited, since it is an area distant from large urban centers.

As to the domains, those with the greatest means were Physical pain, Psychological discomfort, and Psychological disability. Other authors found similar results ${ }^{4,23}$.

Locker ${ }^{24}$ sustains that pain may cause physical or psychological discomfort, or even physical, psychological or social disability, described by the author as limitation or failure in the ability to perform some daily task. The final consequence is the disadvantage, which may be, for example, difficulty in finding employment due to speech pronunciation problems ${ }^{25}$.

Considering that the activities carried out by the TAEs from UFJF are characterized by multiple functions and that, for the most part, these 
functions include maintaining direct contact with the public, this makes the worker concerned about his/her appearance, including the aspect of his/her teeth and mouth. Therefore, one can understand that the psychological discomfort and psychological disability have been the two most affected dimensions.

Pena and Minayo-Gomes ${ }^{26}$ affirm that the differentiating element of the service sector for workers' health is the more direct relation with the client or user inserted into the working process. A smile and facial expression, dissociated from affection/warmth, and standardized beauty are incorporated into the service's work process, as per racial, sexual, and age criteria among others ${ }^{26}$.

As to the frequency of impact of each dimension, one can say that it was low. The dimensions that had the most frequent impact were Physical pain and Psychological discomfort, similar to others studies ${ }^{7,8}$.

A possible explanation for the low frequencies of the impact of oral health on QL found in this study may be the use of dental services by the workers, since most stated that they sought these services for revisions and many for treatment. These workers, besides having financial conditions to pay for private dental services, are inserted into institutions that provide dental insurance or a dental plan.

In the present study, the sex variable had no association with the impact of oral health on the QL of the workers, similar to what was found in other studies ${ }^{7,8,12,27}$.

The age variable maintained a statistically significant association between the OHIP-14 and the older individuals (45 to 67 years), showing a greater impact on QL than on the other younger ones (20 to 44 years). A similar result was found in other studies ${ }^{9,12,18,27}$. However, Bombarda-Nunes et al. ${ }^{8}$ found no statistically significant differences as to age range.

The variable, 'reason for dental appointment', also maintained an association with the significance of the impact. The workers who sought dental care for revision, prevention, or check-up showed a smaller impact on QL than those who sought care due to pain, extractions, treatments, and others. This is a result similar to the study done by Mesquita and Vieira ${ }^{12}$ and Chapelin et al. ${ }^{27}$ who verified that those who sought dental service due to an emergency had a greater impact, which is similar to other studies ${ }^{8,18}$.

Pain is the primary motive that leads adults to seek dental care, and usually these individuals sporadically use the dental service, only when they have symptoms. Worsening of oral health conditions and in parallel, the increased prevalence of dental pain in the adult population are a consequence of the historic and systematic exclusion of this population group from public services that concentrate their attention on schoolage population, and pregnant woman and babies, privileging individual and curative attention ${ }^{28}$.

Slade and Spencer ${ }^{25}$ sustain that the use of dental services routinely improves the quality of life of the population. The onus of the disease could diminish with attention directed towards the individuals who present with a standard of dental visits that is symptomatic and irregular. Additionally, one could say that if the workers sought the dental service more often in a preventive manner, possibly the constant absences from work due to dental reasons, leaves of absence or discomfort at work would be lesser, or even avoided.

Pain exerts an important impact on the QL of individuals due to the suffering and limitations caused in their daily lives. However, little is known about the prevalence of orofacial pain and its impact on the daily lives of workers in Brazil $^{10}$.

One might say that TAEs, since they have incomes that allow paying for dental treatment, are the workers who most seek these services. Also, Mesquita and Vieira ${ }^{12}$ affirm that servers in qualified functions, with higher salaries and better control of time, find it easier to have access to dental treatment. This explains the fact of most workers seeking the dental service for revision, prevention, and a large part for treatment, as was mentioned above.

The 'self-reported need for treatment' variable did not maintain a statistically significant association with OHIP-14. Other authors found associations between the self-reported need for treatment and impact on quality of life ${ }^{9,19,20}$. Barcellos and Loureiro ${ }^{29}$ affirm that the perception of need may be considered a strong predictor of the use of services.

The perception of oral health maintained a significant association with the OHIP-14. The workers that perceived their oral health as good, suffered a smaller impact, a finding similar to that of other studies ${ }^{9,12}$.

The perception of oral condition and the importance given it are what condition the individual's behavior. Almost always the reason people do not seek dental care is the fact that they do not perceive their needs. Thus, it is extremely important to take into consideration the manner 
in which the population itself perceives its own aspects of health and oral diseases ${ }^{22}$.

The variable, 'satisfaction with teeth and mouth' maintained a significant association with the OHIP-14. The workers who stated being satisfied showed the least impact of oral health on $\mathrm{QL}$, a finding similar to that of the study by $\mathrm{Pa}-$ paioannou et al. ${ }^{21}$.

It was observe that at the same time in which most workers perceive their oral health as good and show a low impact of oral health conditions on their quality of life, they also affirm that they need treatment. As per Alvarenga et al. ${ }^{7}$, when there are multiple psychosocial measurements of quality of life, we observe that the field of oral health is not an exception. Very likely, the individuals are content with little in this area, nurturing low expectations in terms of oral health.

It was important to observe the high frequency of the answer 'never' for all the questions of OHIP-14, a result also observed in the study conducted by Silva et al.$^{23}$. Such a fact leads us to reflect that almost all the workers studied did not consider that they had oral problems, and consequently, this is had not affected their social lives. Thus, one can affirm that if the worker thinks everything's fine, he/she possibly does not perceive any oral health problem that will impact his/her QL.

Macedo and Queluz ${ }^{11}$ affirmed that there are few reports in literature on oral conditions in adults, as well as a scarcity of collective health programs structured for this economically active population.

The discrepancies found among the populations studied and even among the individuals occur due to the influence of the cultural context and of the values in perception of quality of life, which confirms the subjectivity of the concept.

In face of the results, we can say that, considering that the data gathered refers to the perception of the workers studied and are not data from clinical examinations, oral health condi- tions have a reduced impact on their quality of life. Additionally, the reduced impact might be explained by the fact of this population having good financial resources, a high level of schooling, and ease of access to dental services.

One can also sustain that the perception of the workers is consistent with the analysis of the variables of health used to explain the study (reason for dental appointment, perceived oral health, and satisfaction with teeth and mouth).

It is important to consider that subjective questions and psychological aspects be considered as essential as normative needs. Additionally, the introduction of the model of social determination of the health/illness process as a philosophy of work, valuing the patient and making him/her co-responsible for determining the priorities in dental treatment is an evident need.

The OHIP-14 could be useful for planning programs and actions focused on workers' health, giving priority to workers with greater psychosocial impacts produced by oral problems. It is necessary to prepare programs based no equity in order to decrease inequalities and their negative effects on people's quality of life.

Thus, actions guided towards education in health, with an emphasis on self-perception and self-care, should be better explored, since they would enable greater empowerment of workers to act with more autonomy in seeking improved quality of life and health.

As to the limitations of the study, we need to point out that since the sample was composed only by Technical Administrative workers in Education, the results found in this study are representative of the individuals studied, and cannot be generalized for the entire population of workers at UFJF. As the entire study is cross-sectional in nature, the analyses made are limited in interpretation by temporality, as well as by a homogeneous sample, particularly in the socioeconomic aspects, which certainly influences the access to services and perception of health. 


\section{Collaborations}

MJC Guerra worked in the concept of the study, methodology, data collection, analysis, and final text of the article. RM Greco and ICG Leite participated in the concept of the study, in methodology, data analysis, final text and approval of the article. EF Ferreira and MVQ Paula participated in preparation of the text and final approval of the article.

\section{References}

1. Sales Peres SHC,Theodoro DS, Ribeiro DA, Avila ED, Greghi GA, Silva RPR. Odontologia do trabalho: doenças e lesões na prática profissional. Rev Fac Odontol Araçatuba 2006; 27(1):54-58.

2. Pizzatto E, Garbin CAS. Odontologia do trabalho: implantação da atenção em saúde bucal do trabalhador. Odontol Clin-Cient 2006; 5(2):99-102.

3. Mendonça BMC, Cimões R, Araújo ACS, Caldas Júnior AF, Silva PV. Impacto do número de dentes presentes no desempenho de atividade diárias: estudo piloto. Cien Saude Colet 2010; 15(3):775-784.

4. Gomes AS, Abegg C. O impacto odontológico no desempenho diário dos trabalhadores do departamento municipal de limpeza urbana de Porto Alegre, Rio Grande do Sul, Brasil. Cad Saude Publica 2007; 23(7):1707-1714.

5. Petersen PE. The World Oral Health Report 2003: continuous improvement of oral health in the 21st century - the approach of the WHO Global Oral Health Programme. Community Dent Oral Epidemiol 2003; 31(Supl. 1):3-24.

6. Minayo MCS, Hartz ZMA, Buss PM. Qualidade de vida e saúde: um debate necessário. Cien Saude Colet 2000; 5(1):7-18

7. Alvarenga FAS, Henriques C, Takatsui F, Montandon AAD, Telarolli Júnior R, Monteiro ALCC, Pinelli C, Loffredo LCM. Impacto da saúde bucal na qualidade de vida de pacientes maiores de 50 anos de duas instituições públicas do município de Araraquara-SP, Brasil. Rev Odontol UNESP. 2011; 40(3):118-124.

8. Bombarda-Nunes FF, Miotto MHMB, Barcellos LA. Autopercepção de Saúde Bucal do Agente Comunitário de Saúde de Vitória, ES, Brasil. Pesqui Bras Odontopediatria Clin Integr 2008; 8(1):7-14.

9. Coelho MP, Cordeiro MCP, Corrêa FF, Carvalho CM, Araújo VE. Avaliação do impacto das condições bucais na qualidade de vida medido pelo instrumento OHIP14. UFES Rev Odontol 2008; 10(3):4-9.

10. Lacerda JT, Ribeiro JD, Ribeiro DM, Traebert J. Prevalência da dor orofacial e seu impacto no desempenho diário em trabalhadores das indústrias têxteis do município de Laguna, SC. Cien Saude Colet 2011; 16(10):4275-4282.

11. Macedo CG, Queluz DP. Quality of life and self-perceived oral health among workers from a furniture industry. Braz J Oral Sci 2011; 10(4):226-232.

12. Mesquita FAB, Vieira $S$. Impacto da condição autoavaliada de saúde bucal na qualidade de vida. RGO 2009; 57(4):401-406.

13. Montero J, López JF, Vicente MP, Galindo MP, Albaladejo A, Bravo M. Comparative validity of the OIDP and OHIP-14 in describing the impact of oral health on quality of life in a cross-sectional study performed in Spanish adults. Med Oral Patol Oral Cir Bucal 2011; 16(6):816-821.

14. Afonso-Souza G, Nadanovsky P, Werneck GL, Faerstein E, Chor D, Lopes CS. Confiabilidade teste-reteste do item único de saúde bucal percebida em uma população de adultos no Rio de Janeiro, Brasil. Cad Saude Publica 2007; 23(6):1483-1488.

15. Brasil. Ministério da Saúde (MS). Pesquisa nacional de saúde bucal - SBBrasil. [acessado 2011 nov 7]. Disponível em: http://dab.saude.gov.br/CNSB/outras_acoes. php 
16. Sanders AE, Slade GD, Lim S, Reisine ST. Impact of oral disease on quality of life in the US and Australian populations. Community Dent Health 2009; 37(2):171181.

17. Associação Brasileira de Empresas de Pesquisa (ABEP). Critério de classificação econômica do Brasil. [acessado 2013 fev 7]. Disponível em: http://www.abep.org/novo/ Content.aspx?ContentID $=835$

18. Miotto MHMB, Barcellos LA, Velten DB. Avaliação do impacto na qualidade de vida causado por problemas bucais na população adulta e idosa em município da Região Sudeste. Cien Saude Colet 2012; 17(2):397-406.

19. Cohen-Carneiro F, Souza-Santos R, Rebelo MAB. Quality of life related to oral health: contribution from social factors. Cien Saude Colet 2011; 16(Supl.1):10071015.

20. Oliveira BH, Nadanovsky P. Psycometric properties of the Brazilian version of the oral health impact profile-short form. Community Dent Oral Epidemiol 2005; 33(4):307-314.

21. Papaioannou W, Oulis, CJ, Latsou D, Yfantopoulus J. Oral Health-Related Quality of Life of Greek Adults: A Cross-Sectional Study. Int J Dent. 2012; 2011:360292.

22. Silva SRC, Fernandes RAC. Autopercepção das condições de saúde bucal por idosos. Rev Saude Publica 2001; 35(4):349-355.

23. Silva MES, Villaça EL, Magalhães CS, Ferreira EF. Impacto da perda dentária na qualidade de vida. Cien Saude Colet 2010; 15(3):841-850.

24. Locker D. Deprivation and oral health: a review. Community Dent Oral Epidemiol. 2000; 28(3):161-169.

25. Slade GD, Spencer AJ. Development and evaluation of the oral health impact profile. Community Dent Health 1994; 11(1):3-11.

26. Pena PGL, Minayo-Gomes C. Premissas para a compreensão da saúde dos trabalhadores no setor serviços. Saude Soc 2010; 19(2):371-383.

27. Chapelin CC, Barcellos LA, Miotto MHMB. Efetividade do tratamento odontológico e redução de impacto na qualidade de vida. UFES Rev Odontol 2008; 10(2):46-51.

28. Lacerda JT, Simionato EM, Peres KG, Peres MA, Traebert J, Marcenes W. Dor de origem dental como motivo de consulta odontológica em uma população adulta. Rev Saude Publica. 2004; 38(3):453-458.

29. Barcellos LA, Loureiro CA. O público do serviço odontológico. UFES Rev Odontol 2004; 6(2):41-50.

Article submitted 30/10/2013

Approved 17/02/2014

Final version submitted 25/02/2014 